Res Publica. Revista de Historia de las Ideas Políticas

ISSN: $1576-4184$

http://dx.doi.org/10.5209/RPUB.56474

\title{
El punto de vista moral de la filosofía política de Otfried Höffe
}

\author{
Oscar Cubo Ugarte*
}

Recibido: 08 de marzo de 2016 / Aceptado: 10 de mayo de 2017

Resumen: La base angular de la filosofía política de Otfried Höffe es la legitimación del "punto de vista moral" para desarrollar los principios de la justicia política. Desde el comienzo de su producción filosófica Höffe ha mantenido y defendido el "punto de vista moral" como el elemento normativo clave para afrontar las grandes cuestiones de la filosofía política. Las deficiencias normativas del anarquismo, así como la completa desmoralización del derecho por parte del positivismo jurídico constituyen el punto de partida para la construcción de su teoría acerca de la justicia política.

Palabras claves: justicia; moral; anarquismo; positivismo jurídico; estado de naturaleza y jurídico.

\section{[en] The moral point of view of Otfried Höffe's political philosophy}

\begin{abstract}
The angular basis of political philosophy in Otfried Höffe is the legitimization of the "moral point of view" to develop the principles of political justice. Since the beginning of his philosophical career Höffe's work has maintained and defended the "moral point of view" as the key regulatory element to tackle crucial issues of political philosophy. The normative deficiencies of anarchism, and the complete demoralization of the law by legal positivism constituted the starting point for the construction of his theory of political justice.
\end{abstract}

Keywords: justice; moral; anarchism; legal positivism; nature and juridical state.

Sumario: 1. Introducción 2. La teoría de la justicia política de Otfried Höffe. 3. Los principios de la justicia política: la ventaja distributiva y la justicia como intercambio. 4 . El ideal normativo de un ordenamiento jurídico-estatal "justo".

Cómo citar: Cubo Ugarte, Ó. (2017). El punto de vista moral de la filosofía política de Otfried Höffe, en Res publica 20.2, 341-355.

\section{Introducción}

La adopción del punto de vista moral significa para Otfried Höffe, en términos puramente éticos, la posibilidad de formular juicios morales universalmente válidos. Dicha exigencia de universalidad es al mismo tiempo la exigencia de adoptar un punto de vista imparcial y neutral que resulte aceptable para cualquiera. La formulación más refinada de esta exigencia de universalización la ofrece, según Höffe, la "fórmula universal" del imperativo categórico. Las distintas formulaciones que ofrece Kant

\footnotetext{
Fern Universität Hagen

Oscar.CuboUgarte@FernUni-Hagen.de
} 
acerca del mismo ponen de relieve la necesidad moral de determinar la universalidad de las máximas como principios subjetivos de la acción. Para el establecimiento del carácter moral o inmoral de las mismas hay que examinar, en primer lugar, si se puede pensar (denken) una máxima como una ley universal, y en segundo lugar, si se puede querer (wollen) que una máxima se convierta en una ley universal. En ambos casos, únicamente las máximas universalizables son conformes con el "punto de vista de la moral" en cuanto tal. Una máxima que se puede universalizar sin más es un principio subjetivo de acción, cuya validez no depende de los intereses personales de ésta o aquélla persona; por este motivo, se trata en este caso de una máxima válida para cualquier ser racional ${ }^{1}$.

En segundo lugar, y este es el aspecto más importante para Höffe, la función normativa del "punto de vista moral" no sólo abarca el enjuiciamiento moral de las acciones individuales de los hombres, sino también el valor moral de las instituciones políticas. Frente a la "tesis de la separación" (Trennungsthese) característica del positivismo jurídico, según la cual el derecho es únicamente "aquello que el legislador político (venga este democráticamente elegido o no) establece como derecho conforme a un procedimiento jurídicamente institucionalizado"2, Höffe enfatiza la función crítica del "punto de vista moral" para la valoración normativa de las instituciones jurídicas y políticas. Mientras que el positivismo jurídico mantiene que no hay ninguna relación necesaria entre la moral y el derecho, de modo que toda investigación científica del derecho debe restringirse al derecho positivo "sin preguntarse cómo debería de ser o cómo debería formarse" ${ }^{3}$, Höffe defiende la existencia de un vínculo esencial entre la moral y el derecho. Numerosas experiencias políticas del siglo XX ponen de relieve el sentido que tiene la expresión "injusticia" (Unrecht) en el plano de las instituciones jurídico-estatales. También casos menos espectaculares, pero igualmente importantes, como la lesión de derechos fundamentales por medio de la prisión arbitraria, el ejercicio de la tortura, la explotación económica o la represión de minorías culturales o religiosas, ponen de relieve, según Höffe, que es necesario conectar el "punto de vista moral" con el análisis de las instituciones políticas.

Esta conexión está ya presente, según Höffe, en el uso coloquial del lenguaje, cuando se enjuician de manera ordinaria las instituciones sociales y políticas. Este tipo de juicios presentan tres rasgos fundamentales: en primer lugar, en tanto que juicios sobre la justicia expresan valoraciones políticas que pretenden tener una validez objetiva; en segundo lugar, por medio de estos juicios se enjuicia la cualidad moral de las instituciones sociales y, en tercer lugar, en este tipo de juicios las valoraciones técnicas o pragmáticas quedan subordinadas a consideraciones morales que constituyen la última autoridad normativa a la hora de enjuiciar las instituciones sociales ${ }^{4}$. El

Cf. O. Höffe, “Der Standpunkt der Moral: Utilitarismus oder Universalisierbarkeit?”, en K-O. Apel, D. Böhler, G. Kadelbach (eds.), Praktische Philosophie/Ethik: Dialoge, vol. 2, Frankfurt/M. Suhrkamp, 1984, p. 49. En el caso de las obras de Höffe las citas de textos no disponibles al castellano siempre las hemos traducido nosotros. Lo mismo cabe decir de los textos de la literatura secundaria de los que no hay disponible una traducción al castellano.

2 J. Habermas, Facticidad y validez. Sobre el derecho y el Estado democrático de derecho en términos de teoría del discurso, Madrid, Trotta, 2008, p. 535.

3 H. Kelsen, Teoría pura del derecho, Buenos Aires, Eudeba, 2009, p. 19.

4 Cf. W. Kersting, "Eine Theorie des Politischen Gerechtigkeit. Otfried Höffes Grundlegung einer kritischen Philosophie von Recht und Staat", en Zeitschrift für philosophische Forschung 43-3, Berlin/Boston, Walter de Gruyter, 1989, p. 476. 
empleo de los predicados "justo/injusto" referidos a las instituciones políticas tiene como fin la legitimación o deslegitimación de dichas instituciones desde un punto de vista estrictamente moral. Así, cuando por ejemplo expresamos nuestra absoluta disconformidad con el régimen nacionalsocialista o con la construcción jurídica de las dictaduras socialistas, no estamos expresando un juicio de carácter técnico o pragmático, sino un juicio decididamente moral. Además, estos juicios de valor no se dirigen en primer lugar contra individuos concretos (este o aquel político, soldado o juez) o contra un responsable político determinado, sino que se dirigen fundamentalmente a la estructura jurídica del Estado. Dicho de otro modo, el "punto de vista moral" presupuesto en este tipo de juicios implica la existencia de principios normativos mínimos que todo ordenamiento jurídico debe cumplir para no ser injusto.

De esta manera, la perspectiva moral de la justicia política introduce una importante diferencia conceptual entre la legalidad de un ordenamiento jurídico positivo y su legitimidad, esto es, entre el principio de legalidad inmanente a todo ordenamiento jurídico y el punto de vista de la legitimidad política que constituye el punto de vista propio de la justicia política. A partir de la disociación de la legalidad de ciertas instituciones políticas, así como de la legalidad y constitucionalidad de ciertas leyes en el interior de un ordenamiento jurídico positivo, y la legitimidad de las mismas se gana el espacio normativo para enjuiciar las instituciones políticas. De este modo la cuestión de la legalidad o de la validez de las normas del derecho positivo se amplía con la pregunta acerca de la legitimidad de las mismas y del orden constitucional que las acoge. En virtud de la adopción del mencionado "punto de vista moral" se puede valorar los ordenamientos jurídicos positivos desde el punto de vista de su legitimidad.

Ganar este espacio normativo es la tarea previa fundamental de una teoría acerca de la justicia política. Así, junto al principio de legalidad que instaura toda constitución positiva Höffe insiste en la necesidad de desplegar el punto de vista de la justicia política. Para Höffe no es, por tanto, posible eludir la pregunta acerca de si es "justo" o no un determinado sistema jurídico ni, por tanto, omitir la pregunta acerca de su legitimidad política. Los criterios para responder a dicha cuestión ha de sacarlos a la luz la teoría de la justicia política, que para Höffe tienen que desplegarse en dos pasos: en primer lugar, abordando el problema de la legitimación de la coacción estatal en cuanto tal y, en segundo lugar, destilando los principios mínimos de la justicia política.

Una teoría completa de la justicia política tiene, pues, que ofrecer una legitimación de la competencia coactiva del derecho y del Estado, que en sí misma no es evidente, ya que implica un elemento de violencia ajeno a la idea de libertad individual y, en segundo lugar, una respuesta a la cuestión de cómo deben organizarse las instituciones políticas para obtener el calificativo de "justas". Höffe emprende la primera tarea de legitimación por medio de una discusión teórica con las premisas normativas del anarquismo, para el que toda coacción jurídico-estatal es ilegítima, la segunda tarea con una refutación del positivismo jurídico para el que la adopción de un "punto de vista moral" a la hora de juzgar la legitimidad de las instituciones políticas supone salirse del principio de legalidad propio de la jurisprudencia.

En definitiva, los principios de la justicia política tienen que mostrar, según Höffe, que resulta racional y legítima la coacción asociada al derecho y al Estado, y al mismo tiempo ofrecer los criterios que todo orden jurídico positivo tiene que satisfacer para poder ser considerado como un sistema político justo. 
Los principios de la justicia política parten del hecho de que la dominación es necesaria pero no todas sus formas están éticamente justificadas. Mientras que rechazan como estrictamente ilegítima la dominación en el sentido del despotismo y la opresión, propician un orden de dominación que satisfaga criterios racionales. La justicia política no consiste en la superación sino en la transformación cualitativa de la dominación ${ }^{5}$.

Esta transformación cualitativa de la dominación tiene lugar cuando ésta realiza en sus instituciones los principios de la justicia política, deviniendo con ello una condición indispensable para la libertad.

\section{La teoría de la justicia política de Otfried Höffe}

Höffe elabora las ideas fundamentales de su teoría de la justicia en su monografía Justicia politica ${ }^{6}$ publicada en 1987, y con posterioridad en su obra Demokratie im Zeitalter der Globalisierung (Democracia en la era de la globalización) de 1999, sobre todo, en su primer apartado titulado: "Qualifizierte Demokratie". No obstante, y desde finales de los años setenta la investigación acerca de los principios normativos de un ordenamiento político "justo" constituye uno de los hilos conductores de la filosofía política de Höffe ${ }^{7}$. En este texto defiende que la limitación política de la libertad, para ser legítima, ha de realizarse "con arreglo a principios estrictamente universales y válidos de una manera igual para todos"8.

Esta idea recorre por entero el libro Justicia política que Höffe publica a finales de los años ochenta. En su reseña a este libro, titulada los "Límites del normativismo iusnaturalista", Habermas describe la disposición arquitectónica de la Justicia política del siguiente modo: en primer lugar, como una discusión crítica "contra las concepciones positivistas del derecho y del Estado y contra la utopía anarquista de la ausencia de dominio", en segundo lugar, como "una perspectiva deontológica de la justicia" a partir de un minucioso análisis de un estado de naturaleza jurídico y, en tercer lugar, como "una legitimación iusnaturalista de los derechos humanos"10.

El punto de partida de la justicia política lo constituye la discusión teórica con el anarquismo y el positivismo jurídico, que es la "antinomia de lo político"11 de la modernidad. El primer paso para escapar de esta antinomia de lo político consiste en la legitimación de la facultad coactiva del derecho y del Estado frente a las tesis anarquistas. Como "anarquistas" cabe caracterizar a todas aquellas teorías sociales que denuncian en términos normativos todo tipo de poder o de dominación política como elementos incompatibles con el principio de la libertad individual de cada per-

O. Höffe, Estudios sobre teoría del derecho y la justicia, Buenos Aires, Fontamara 2004, p. 9.

6 Disponemos de una traducción parcial de la misma de Juan Carlos Velasco: O. Höffe, Justicia política. Fundamentos para una filosofia crítica del derecho y del Estado, Barcelona, Paidós, 2003.

7 Destaca especialmente su trabajo "Herrschaftsfreiheit oder gerechte Herrschaft" ("Libertad de dominación o dominación justa) que conforma el último capítulo del libro Ethik und Politik. Grundmodelle und -probleme der praktischen Philosophie, Frankfurt/M, Suhrkamp, 1979.

$8 \quad$ O. Höffe, Ethik und Politik. Grundmodelle und-probleme der praktischen Philosophie, op. cit., p. 415.

9 J. Habermas, La necesidad de la revisión de la izquierda, Madrid, Tecnos, 1991, pp. 101-116.

$10 \quad$ Ibidem, p. 103.

11 O. Höffe, Politische Gerechtigkeit, op. cit., p. 23 (2003, p. 55). 
sona. El anarquismo político rechaza la coacción jurídico-estatal y al mismo tiempo defiende la autoorganización espontánea y armónica de los sujetos en un contexto de cooperación social sin ningún ejercicio de dominio político.

Desde este punto de vista, la dominación política y la facultad coactiva asociada al Estado resultan ilegítimos. Dicho de otro modo, los conceptos de "legitimidad" y de "dominación política" se excluyen mutuamente, por lo que carece de sentido hablar de una dominación estatal legítima o justa. El único modo legítimo de coexistencia entre los seres humanos sería aquel en el que no hay ningún tipo de dominación política y de carácter jurídico-estatal. La ausencia de dominio constituye, pues, la condición indispensable para una sociedad justa, por lo que hablar de una dominación política justa bajo el prisma de la justicia política no es sino una contradictio in adiecto en la que se intentan conjugar términos absolutamente contrapuestos como son la libertad individual y la dominación política. Bajo el supuesto de que la libertad de dominio constituye el pilar fundamental de una sociedad libre, el anarquismo tacha como "ilegítimo cualquier ordenamiento jurídico estatal"

Para refutar la premisa central de las teorías anarquistas Höffe recupera de las teorías contractualistas el experimento de un estado de naturaleza jurídico, donde las interacciones sociales no estarían reguladas jurídicamente. Lo que muestra dicho experimento es que este estado de naturaleza no es un estado idílico libre de conflictos, tal y como suponen los teóricos anarquistas, sino un escenario de latente conflictividad en el que todos sus habitantes están expuestos a una limitación arbitraria de su libertad por parte de los demás. La razón última de la conflictividad estructural del estado de naturaleza primario reside, para Höffe, en la mera "coexistencia de unos seres libres junto a otros"13. El estar expuesto a una limitación arbitraria de la libertad constituye, pues, el precio de la ausencia de dominación político-jurídica. Wolfgang Kersting lo expresa del siguiente modo:

si se eliminan de una sociedad todas las regulaciones e instituciones que limitan la libertad, entonces nos encontramos no con el idilio de una libertad no perturbada, sino en un escenario de acciones que limitan la libertad de acción de otros recíprocamente y, por tanto, en un estado de naturaleza conflictual. De modo que la discusión no puede ser sobre la de coacción social o ausencia de coacción, sino sólo acerca del tipo apropiado de coacción. Es decir, la utopía anarquista de la ausencia de coacción y de dominación tiene, pues, que dejar paso a la pequeña utopía política de la justicia de la menor y mejor coacción posible ${ }^{14}$.

Al dejar transcurrir el experimento de un estado de naturaleza Höffe muestra, pues, que dicho escenario es un lugar donde los conflictos sólo se pueden solucionar por medio de la fuerza. Bajo estas condiciones lo que resulta dañado es precisamente el individualismo normativo que postula el anarquismo por la falta de un marco jurídico dentro del cual los individuos puedan ejercer su libertad y resolver sus conflictos.

O. Höffe, Politische Gerechtigkeit, op. cit., p. 19 (2003, p. 51).

Ibidem, p. 335.

14 W. Kersting, "Eine Theorie des Politischen Gerechtigkeit. Otfried Höffes Grundlegung einer kritischen Philosophie von Recht und Staat", en Zeitschrift für philosophische Forschung 43-3, Berlin/Boston, Walter de Gruyter, 1989, p. 484. 
El segundo paso para superar la mencionada antinomia de lo político requiere, según Höffe, una discusión pormenorizada con el positivismo jurídico, cuyo más destacado representante es Hans Kelsen. La crítica de Kelsen a la entera tradición del derecho natural y con ello a la idea de una justicia política en general supone la principal objeción a la que tiene que hacer frente el proyecto de una teoría de la justicia política. El punto de partida de las consideraciones críticas de Kelsen acerca de los discursos sobre la justicia consiste en diferenciar las tareas descriptivas de una ciencia objetiva sobre el derecho positivo en cuanto tal y las reflexiones político-filosóficas acerca de las condiciones normativas que un ordenamiento jurídico positivo ha de cumplir para poder ser considerado como "justo". Una teoría pura del derecho y del Estado no debe preguntarse, pues, si debe existir el Estado ni cómo debe ser, sino qué y cómo es ${ }^{15}$.

La ética política y las distintas posiciones sobre la justicia política se caracterizan en su conjunto por defender un punto de vista metajurídico situado más allá del derecho positivo para enjuiciarlo con arreglo a un patrón normativo ajeno al mismo. Este punto de vista moral es un punto de vista metajurídico que no está necesariamente anclado en el derecho positivo y, por tanto, no puede ser tratado de un modo científico-objetivo. Lo que separa al positivismo jurídico de las teorías acerca de la justicia política es, por tanto, su negación de la validez objetiva de los principios suprapositivos defendidos por aquellas. En este sentido, se puede decir que el positivismo jurídico "no afirma la superioridad del derecho positivo sobre el derecho natural, sino la exclusividad del derecho positivo"16.

La eliminación de las consideraciones acerca de la justicia política permite a la teoría pura del derecho investigar y analizar en términos puramente descriptivos la estructura del derecho positivo más allá de cualquier presupuesto iusnaturalista. Este análisis descriptivo de la estructura del derecho positivo pone de relieve dos aspectos fundamentales del mismo: en primer lugar, su carácter escalonado y jerárquico y, en segundo lugar, que el ámbito de validez del derecho positivo está siempre condicionado espacial y temporalmente. A diferencia de las pretensiones atemporales de validez absoluta de los principios de la justicia política, la validez del derecho positivo está siempre restringida a un ámbito geográficamente delimitado y a los miembros particulares del mismo. A su vez, y como pone de relieve la modificabilidad constitucional de los sistemas jurídicos positivos, el derecho positivo tiene una estructura dinámica, siempre es susceptible de ser modificado. Por último,

bajo este aspecto de cambiabilidad, o de susceptibilidad de cambio, la validez del derecho positivo aparece como la expresión pura de una voluntad que, habida cuenta de la posibilidad siempre presente de derogarlas, presta a determinadas normas una durabilidad discrecional. En este voluntarismo del puro poner, de la posición pura es en el que [...] se enciende el pathos del positivismo jurídico ${ }^{17}$.

$\mathrm{Al}$ analizar la estructura escalonada y jerárquica del derecho positivo, Kelsen se enfrenta al problema de la génesis dinámica del derecho positivo a partir de la primera constitución histórica. La validez normativa de este primer acto constitucional

Cf. H. Kelsen, Teoría pura del derecho, Buenos Aires, Eudeba, 2009, p. 19.

N. Bobbio, El problema del positivismo jurídico, México, Fontamara, 2007, p. 74.

J. Habermas, Facticidad y validez, op. cit., p. 101. 
es a su vez condicional, ya que depende de la suposición de una norma fundamental (Grundnorm) en virtud de la cual los destinatarios de esta primera constitución se deben comportar tal y como queda fijado en la misma ${ }^{18}$. El carácter lógico trascendental de esta suposición priva a la norma fundamental de cualquier contenido normativo suprapositivo. La virtud de su formalidad la norma fundamental no pone en juego un principio iusnaturalista por encima del derecho positivo, sino que sólo saca a la luz el presupuesto lógico para la validez de la primera constitución histórica.

La desmaterialización de la norma fundamental como presupuesto hipotético de la juricidad de la primera constitución histórica ratifica, pues, la tesis fundamental del positivismo jurídico, según la cual no hay ningún fundamento suprajurídico (basado por ejemplo en principios de la justicia) de la dominación política por encima del propio ordenamiento jurídico, con lo que así se asegura la autonomía y soberanía del mismo. Esta norma fundamental no puede entrar en conflicto con el derecho positivo vigente, porque carece de contenido normativo específico, por lo que resulta compatible con cualquier ordenamiento jurídico. Igualmente tampoco se puede determinar a través de ella cómo debe estar constituido el derecho positivo, ni tampoco legitimar (o deslegitimar) un ordenamiento jurídico positivo. La norma fundamental no fija ningún límite sustancial al contenido del derecho positivo, porque no da ninguna prescripción material al mismo.

Para Kelsen, la función ideológica y claramente política de las teorías acerca de la justicia política se hace patente en el hiato que ellas abren entre la legalidad y la legitimidad de un determinado sistema jurídico. Las teorías acerca de la justicia política no sólo manejan un concepto extrajurídico de justicia, sino que a través de él proporcionan una legitimación (o deslegitimación) añadida a un determinado ordenamiento jurídico. Tras las teorías de la justicia política se esconden intereses políticos para legitimar o deslegitimar el derecho positivo. Por medio de su legitimación suprapositiva el derecho positivo gana un plus en legitimidad y en caso de su deslegitimación se pone de relieve la necesidad de reformar el orden jurídico vigente. Por el contrario, y en virtud de su carácter enteramente descriptivo, la Teoría pura del derecho como andamiaje teórico del positivismo jurídico, carece de semejante alcance normativo y permanece "neutral" frente al contenido positivo de cualquier ordenamiento jurídico.

En virtud de esta comprensión positivista del derecho, Kelsen considera que el derecho sólo es aquello "que un legislador político, elegido conforme a los criterios establecidos, establece como derecho"19 y que el único criterio de legitimidad es el principio de legalidad, "en virtud del cual todo poder público - legislativo, judicial y administrativo - está subordinado a leyes generales y abstractas, que disciplinan sus formas de ejercicio y cuya observancia se halla sometida a control de legitimidad por parte de jueces separados del mismo e independientes" ${ }^{20}$. Como acertadamente señala L. Ferrajoli, lo que separa al positivismo jurídico de las teorías de la justicia política es su separación definitiva de la validez del derecho positivo de cualquier pauta moral de carácter extrajurídico, puesto que "la moralidad (o la justicia) predicable de una norma no implica su juricidad (o su validez) [...] y la juricidad (o

18 Cf. H. Kelsen, Reine Rechtslehre. Mit einem Anhang: Das Problem der Gerechtigkeit. Wien, Verlag Franz Deuticke, 1960, pp. 203 y 443.

$19 \quad$ Ibidem, p. 368.

20 L. Ferrajoli, Derecho y razón. Teoría del garantismo penal, Madrid, Trotta, 1995, p. 856. 
validez, o pertenencia a un sistema jurídico) de una norma no implica su moralidad (o justicia)"'21.

Sin embargo, esta separación está en el centro de la crítica que Höffe dirige al positivismo jurídico, ya que sin ella simplemente se tiene "un concepto de derecho unidimensional, que no conoce como derecho más que la validez positiva de la normas, y para el que se rechaza toda perspectiva de la justicia, negando con ello la doble dimensión que diferencia la Gültigkeit y la Geltung o la diferencia entre legitimidad y la legalidad, sin la cual una teoría de la justicia pierde su objeto"22. Desde el punto de vista de la justicia política, la dominación política sólo resulta legítima cuando es ejercida dentro de criterios marcos normativos, sin los cuales se estaría dando carta blanca a cualquier forma de dominación política. Dejar atrás la antinomia de lo político requiere, por tanto, superar las teorías anarquistas acerca del derecho y del Estado y las tesis del positivismo jurídico. En el caso de la teoría de la justicia política de Höffe, la legitimación de la dominación política está necesariamente unida a su limitación normativa. La vía para solucionar la "antinomia de lo político" consiste, pues, en

encontrar una postura mediadora que, por un lado, se oponga al positivismo jurídico estricto, sin abandonar por ello completamente el derecho y el Estado, y que, por otro lado, critique al anarquismo, sin otorgar al derecho y al Estado un poder absoluto. En pocas palabras, una posición que aúne el reconocimiento no absoluto con un rechazo igualmente relativo del poder del derecho y del Estado. En la medida en que la justicia política debe proporcionar esta mediación, tiene que ser al mismo tiempo legitimadora y limitadora del poder del derecho y del Estado [...]. No es legítimo cualquier Estado, sino sólo el Estado justo ${ }^{23}$.

\section{Los principios de la justicia política: la ventaja distributiva y la justicia como intercambio}

En su reelaboración del punto de vista moral de la justicia política, O. Höffe sigue la huella de la Teoría de la justicia de John Rawls, y desarrolla su teoría como un contra-modelo al utilitarismo y a los principios normativos que éste emplea para enjuiciar el carácter más o menos eficaz de las instituciones sociales y políticas ${ }^{24}$. La objeción fundamental de Otfried Höffe a la evaluación utilitarista de las instituciones sociales es que éstas no sólo deben ser juzgadas por su eficiencia en relación con el bienestar colectivo que producen, sino por su carácter más o menos justo. Höffe enfrenta el principio de la ventaja distributiva al principio utilitarista de optimizar las instituciones sociales con vistas a obtener el mayor provecho colectivo. El principio de la ventaja distributiva lo desarrolla Höffe en su discusión con los principios normativos del utilitarismo con vistas a obtener "una fundamentación de los derechos

\footnotetext{
21 L. Ferrajoli, Principia iuris. Teoría del derecho y de la democracia. 1. Teoría del derecho, Madrid, Trotta, 2011, p. 16.

22 O. Höffe, Politische Gerechtigkeit, op. cit., p. 114.

23 Ibidem, p. 20-21 (2003, p. 52-53).

24 Cf. J. Rawls, Teoría de la justicia, México, FCE, 2002, pp. 34 ss; J. Rawls, El liberalismo político, Crítica, Barcelona, 2006, p. 295.
} 
inviolables de cada persona individualmente considerada" ${ }^{25}$. Desde un punto de vista moral, el principio de la ventaja distributiva implica que

las limitaciones de la libertad y su carácter coactivo de carácter recíproco deben ser establecidas de manera tal que resulten ventajosas distributivamente. El principio fundamental es, entonces, el de la coexistencia de libertades distributivamente ventajosas. Si ponemos el acento en los inevitables límites de la libertad, podemos hablar también de una limitación distributivamente ventajosa y, si consideramos el beneficio, podemos hablar de un reconocimiento de la libertad distributivamente ventajosa ${ }^{26}$.

Para las teorías utilitaristas tanto las acciones de los individuos como las instituciones políticas son valoradas con arreglo a la utilidad de las mismas. Para el enjuiciamiento moral de las instituciones políticas el utilitarismo requiere de un amplio conocimiento empírico acerca del mundo y en particular de las consecuencias que dichas instituciones puedan tener para el bienestar de sus destinatarios, conocimiento sin el cual no se puede enjuiciar moralmente a las mismas. Para Höffe el punto fuerte del utilitarismo consiste "en que vincula un elemento racional-normativo, el principio de utilidad, con la exigencia de aportar conocimientos empíricos sobre la realidad del mundo" 27 .

Sin embargo, su punto débil reside en que por medio de ambos principios no puede resolver de una manera adecuada el problema de la justicia política, ya que con arreglo al principio de utilidad sólo cabe legitimar una organización social en términos relativos, esto es, cuando por medio de un estudio comparativo se puede mostrar que dicha organización social eleva la suma del bienestar total de sus miembros bajo unas condiciones dadas. Desde este punto de vista y bajo ciertas condiciones dadas, sistemas políticos dictatoriales o instituciones jurídicas como la esclavitud pueden ser consideradas por los utilitaristas como instituciones legítimas, por ofrecer una alternativa mayor utilidad general que escenarios aún más desventajosos para todos.

Igualmente, y con arreglo al mismo principio de utilidad, se puede legitimar políticamente el aumento del bienestar colectivo aun cuando este se produzca a costa del bienestar particular de ciertos individuos. Así bajo ciertas circunstancias, se pueden legitimar instituciones sociales injustas desde el puno de vista de la justicia política por el simple hecho de que aumentan la suma del bienestar colectivo, aun cuando ellas lesionen los derechos de algunos de sus miembros. Dicho de otro modo, el utilitarismo puede llevar a legitimar instituciones políticas manifiestamente injustas en virtud del principio maximizador del bien colectivo. En este sentido, según Höffe, para el utilitarismo "el nivel de satisfacción colectiva merece absoluta prioridad frente a la libertad individual. Una sociedad feudal o esclavista, también un Estado policial o militar - [en la medida en que impliquen] una máxima utilidad total o per cápita de todos los afectados- estarían no sólo éticamente permitidos, sino también éticamente ordenados" ${ }^{\prime 28}$.

O. Höffe, Politische Gerechtigkeit, op. cit., p. 15 (2003, p. 47).

Ibidem, p. 382 (2003, p. 99).

O. Höffe, "Der Standpunkt der Moral: Utilitarismus oder Universalisierbarkeit?”, op. cit., p. 41.

O. Höffe, Estudios sobre teoría del derecho y la justicia, op. cit, p. 10. 
En términos semejantes a Rawls, Höffe considera que la suma total de utilidad de una institución social no sólo es a nivel teórico incalculable, sino que conduce a resultados normativamente intolerables. Ciertamente, las teorías utilitaristas sostienen que hay que considerar a todos y cada uno de los individuos para realizar dicho cálculo, por lo que defienden un cierto igualitarismo a la hora de calcular la utilidad de una determinada institución social. No obstante, en este cálculo adopta un punto de vista totalizador en la medida en que el beneficio global prevalece sobre las pérdidas puntuales de utilidad que para ciertos individuos pueden acarrear ciertas instituciones sociales. El utilitarismo resulta, pues, indiferente y neutral frente a los resultados individuales de dicho cálculo, en virtud del cual una institución social resulta legitimada a partir del cómputo total de su utilidad general.

A partir de estas premisas, el utilitarismo sólo puede ofrecer una legitimación pragmática de la dominación política, puesto que toma en consideración "si en la coacción social, además de la pérdida de libertad, se produce también una ganancia y resulta, por tanto, un balance positivo para la libertad; es decir, si pesa más la ganancia que la pérdida de libertad, entonces la coacción social se muestra como legítima, mientras que el balance negativo significaría su ilegitimidad"29. A los ojos de Höffe el error fundamental del utilitarismo reside en realizar este cálculo acerca de la utilidad social bajo un parámetro colectivo, y no distributivo, tal y como demanda el principio fundamental de la justicia política. Para el utilitarismo lo decisivo reside en alcanzar la máxima utilidad general, de modo que en sus consideraciones resulta irrelevante el reparto de dicha utilidad general entre los distintos miembros de una sociedad, de modo que las pérdidas y perjuicios de unos pueden ser compensados a nivel normativo con un mayor beneficio colectivo. Frente a las consecuencias indeseables que se pueden derivar de este tipo de cálculo, Höffe propone como el principio de la ventaja distributiva como pilar normativo para la valoración moral de las instituciones políticas.

El principio de la ventaja distributiva no tiene como categoría central el concepto de distribución (sobre la que no hay ninguna unanimidad en el debate contemporáneo acerca de la justicia), sino el concepto de intercambio.

A favor del intercambio hay un argumento de estrategia argumentativa. Se debate con vehemencia cuál es el criterio de la justicia distributiva. El liberalismo económico, por ejemplo, dice: a cada cual según su rendimiento; el socialismo en cambio, así como muchos alegatos a favor de la llamada justicia social, demandan: a cada cual según sus necesidades; en el estado de derecho se dice: a cada cual según sus derechos legales; y en la aristocracia: a cada cual según los méritos de sus antepasados. Pero no existe en cambio una discusión seria sobre el fundamento de la justicia del intercambio. Ésta consiste en la igualdad de valor del tomar y el recibir. De modo que sobre el criterio de la justicia del intercambio (la justicia conmutativa) existe acuerdo. Si bien el valor exacto de las mercancías o de los servicios a intercambiar a menudo es controvertido, no resulta controvertido el criterio por el cual se considera justo un intercambio: el principio de la equivalencia. Dar y tomar deben tener igual valor; y allí donde el valor es discutido, debe haber al menos una ventaja recíproca ${ }^{30}$.

O. Höffe, Politische Gerechtigkeit, op. cit., p. 73 (2003, p. 80).

30 O. Höffe, "Justicia política y social como intercambio: Para la fundamentación del derecho, del Estado y del Estado social", en Estudios Públicos no 124, Santiago de Chile, Centro de Estudios Públicos, 2011, pp. 4-5. 
El principio de la ventaja distributiva descansa, pues, en la idea de la justicia como intercambio, esto es, en la reciprocidad simétrica de lo intercambiado. Con arreglo a ello, un cambio es por definición "justo", cuando lo intercambiado tiene el mismo valor. El lema de la justicia como intercambio es, por tanto, "cambia equivalentes". Con arreglo a dicho principio cada uno recibe "algo que resulta equivalente a lo que el otro recibe igualmente. El cambio de equivalentes produce una igualdad entre una prestación y una contraprestación. [...] Esta equivalencia hace que el intercambio sea justo, porque cada uno recibe lo suyo y ninguno da más que el otro a través del intercambio" ${ }^{\prime 31}$. El valor equivalente de lo intercambiado implica, pues, un intercambio estrictamente simétrico en el que ninguno de los implicados padece una desventaja tras efectuar el intercambio. O dicho en términos positivos, "las condiciones para un intercambio recíprocamente beneficioso exigen que cada participante en el intercambio obtenga un beneficio a partir del mismo"32.

La obtención de dicho beneficio significa que por medio del intercambio no se alcanza una posición peor a la que se tenía previamente al mismo, puesto que de ser así no cabría explicar la disposición de llevarlo a cabo, es decir, el resultado del intercambio tiene que resultar positivo para todos los que participan en él o, al menos, como no desventajoso para ninguno de ellos, por lo que su consecución debe prometer una situación más favorable para todos los implicados en el mismo. El principio del intercambio justo supone, pues, un modelo de cooperación en el que "los implicados en el mismo obtienen una posición mejor a la que anteriormente tenían y que no hubieran podido alcanzar sin el otro"33. El principio de la ventaja recíproca ofrece, según Höffe, la clave para discernir a nivel normativo un intercambio "justo" de otro "injusto". Un intercambio resulta injusto cuando provoca un empeoramiento del estado actual de los participantes en el mismo y es justo cuando mejora la posición inicial de todos ellos.

A partir de este criterio se pueden extraer igualmente las dos condiciones imprescindibles para que tenga lugar un intercambio justo:

a nivel subjetivo, es necesario un libre asentimiento y a nivel objetivo, que lo intercambiado tenga el mismo valor, o por lo menos no muestre una desigualdad de valor importante. Es decir, justo no es un cambio en el que se aprovecha del otro por medio de una situación coactiva o por medio de una situación de apuro, que presione a uno de los participantes en el cambio, [...], ni tampoco un intercambio en el que lo intercambiado no tenga el mismo valor ${ }^{34}$.

La ausencia de coacción, así como la ausencia de engaños con vistas a conseguir una mejora unilateral en el intercambio constituyen las dos condiciones negativas contenidas en el principio de la ventaja distributiva. La teoría de la justicia como intercambio presupone, pues, en términos positivos un modelo de cooperación entre iguales basado en la reciprocidad y el beneficio mutuo.

31 P. Koslowski, Prinzipien der Ethischen Ökonomie, Tübingen, J. C. B. Mohr, 1994, p. 228.

$32 \quad$ Ibidem, p. 241.

33 W. Kersting, "Herrschaftslegitimation, politische Gerechtigkeit und transzendentaler Tausch. Eine kritische Einführung in das politische Denken Otfried Höffes", en W. Kersting (ed.), Gerechtigkeit als Tausch?. Auseinandersetzungen mit der politischen Philosophie Otfried Höffes, Frankfurt/M., Suhrkamp, 1997, p. 55.

34 O. Höffe, Demokratie im Zeitalter der Globalisierung, Munich, Beck, 1999, p. 55. 
De este modo, y a diferencia del principio utilitarista de la utilidad colectiva de una institución social, el principio de la ventaja distributiva parte de que el carácter justo de las instituciones sociales depende del beneficio que ellas reportan a cada uno de sus miembros. Desde el punto de vista de la ventaja distributiva se puede reconstruir la legitimidad de las instituciones estatales por su capacidad de generar un asentimiento universal entre todos y cada uno de los miembros de la sociedad. El principio de la ventaja distributiva permite a su vez reconciliar el "punto de vista moral" y el punto de vista de la "racionalidad práctica", ya que impide tratar a los individuos como medios para un cálculo de utilidad colectiva y al mismo tiempo permite a todos ellos satisfacer su propio interés sin que ello tenga lugar a costa del interés de los demás. Igualmente, el principio de la ventaja distributiva se atiene al requisito de la imparcialidad, ya que "allí donde la praxis humana se enjuicia conforme al beneficio que ofrece para todos no se toma partido por un individuo, ni tampoco por un grupo, sino distributivamente por todos. La consideración de la justicia como toma de partido por cada uno se corresponde con la idea de imparcialidad" ${ }^{\prime 35}$.

La prioridad normativa al principio del beneficio mutuo frente al principio utilitarista de la utilidad media de una determinada institución social se debe a que el principio de la ventaja distributiva nunca "se dirige en contra de los intereses de los afectados. Sólo se preocupa de que no haya dos clases de afectados, uno de los cuales obtiene los beneficios y el otro sólo los perjuicios" ${ }^{\text {36. }}$. En términos institucionales esto significa que ninguna institución social puede sustentarse normativamente en el aumento de un beneficio medio, si ello implica el sacrificio unilateral de los beneficios de algunos de sus miembros, y en términos particulares, que la búsqueda particular del propio interés no debe realizarse a costa de la búsqueda de los demás.

\section{El ideal normativo de un ordenamiento jurídico-estatal "justo"}

A partir del principio de la ventaja distributiva quedan desacreditadas todas las instituciones sociales que no distribuyan las ventajas de la cooperación social de manera igual entre todos sus miembros. No obstante, el principio de la ventaja distributiva desempeña un doble papel dentro de la justicia política de Höffe. En su versión débil este principio permite legitimar la instauración de un ordenamiento jurídico estatal, sea cual sea el contenido que adopte el mismo, como alternativa favorable al estado de naturaleza prejurídico. Sin embargo, en su versión fuerte, esto es, en su versión completa, el principio de la ventaja distributiva ofrece una directriz para reformar en términos igualitarios todo ordenamiento jurídico-estatal, con vistas a que pueda ser calificado de "justo". En efecto, Höffe es consciente de que el criterio de la ventaja distributiva es susceptible de dos interpretaciones diferentes: "de acuerdo con el sentido débil de la justicia política, basta con que la competencia coercitiva suponga un beneficio para cada uno; según el sentido fuerte, el beneficio debería de ser igual en todos los casos" ${ }^{\prime 37}$; para la legitimación de un orden social con competencia coercitiva, basta con el sentido más débil, mientras que para la legitimación de un ordenamiento jurídico como un sistema jurídico justo es necesario presuponer

\footnotetext{
O. Höffe, Politische Gerechtigkeit, op. cit., p. 83 (2003, p. 90).

O. Höffe, Estudios sobre teoría del derecho y la justicia, op. cit., p. 73.

O. Höffe, Politische Gerechtigkeit, op. cit., pp. 79-80 (2003, pp. 86-87).
} 
la repartición equitativa de las cargas y los beneficios de la cooperación social. Para ilustrar el sentido fuerte del principio de la ventaja distributiva conviene contrastarlo con el famoso "principio del provecho mutuo" que defienden teorías neo-contractualistas como, por ejemplo, la de J. Buchanan.

Con arreglo al "principio del provecho mutuo" toda dominación política y toda forma de Estado son "justas" cuando se erige sobre el consentimiento y el provecho mutuo de todos sus integrantes. Según este criterio, se puede legitimar la salida del estado de naturaleza y la instauración de un ordenamiento jurídico por el simple hecho de que dicho tránsito resulta provechoso para todos sus miembros. Desde este punto de vista, una dominación política es justa "con tal de que sea mejor para todas partes que la alternativa de la lucha" 38 . Esto hace que el enjuiciamiento moral de las instituciones sociales descanse única y exclusivamente en una apreciación comparativa y relativa de su beneficio frente a una situación pretérita más desventajosa. Así, se responde en un primer momento a la pregunta legitimatoria de la dominación política como una alternativa más ventajosa que el estado de naturaleza, sea cual sea su contenido. Cualquier ordenamiento jurídico siempre será mejor que el conflicto permanente intrínseco al estado de naturaleza prejurídico.

El "principio del provecho mutuo" ofrece también en términos formales un criterio suficiente para reformar el orden constitucional, que será legítimo cuando implique una mejora jurídica para sus destinatarios en comparación con el orden constitucional anterior; es decir, cualquier reforma constitucional podrá considerarse como justa, siempre que dicha reforma suponga una mejora respecto de un estado (constitucional) precedente reflejando con ello una nueva relación de fuerzas en su interior. De este modo, con arreglo al "principio del provecho mutuo" han de considerarse legítimas y justas a todas las reformas políticas que supongan un aumento y mejora de la posición inicial entre las partes dentro del nuevo orden constitucional. El punto débil de dicho principio es, sin embargo, que "pueden darse sistemas de cooperación mutuamente ventajosos que permitan una distribución muy desigual de las ventajas" 39 . Este aspecto está en el centro del principio de la ventaja distributiva, que no sólo permite justificar la dominación política en general, sino que implica también las condiciones mínimas que deben satisfacer todo ordenamiento jurídico para ser enjuiciado como "justo". Frente a la teoría económica de la justicia de Buchanan y su "principio del provecho mutuo", el principio de la ventaja distributiva de Höffe diseña un punto de equilibrio igualitario en la distribución de las cargas y de las ventajas de la cooperación social.

La forma institucional que garantiza este reparto equitativo de las cargas y beneficios sociales es denominado por Höffe "Estado constitucional democrático y de derecho". La versión fuerte del principio de la ventaja distributiva lo que viene a expresar es lo siguiente: sólo el reparto equitativo de las cargas y de los beneficios de la cooperación social pone punto y final al reparto injusto de los mismos. Mientras no se alcance este reparto equitativo el orden constitucional siempre será en términos normativos inestable, porque no podrá ser consensuado en su interior por la distribución desigual de las cargas y de las ventajas de la cooperación social. La repartición imparcial de las ventajas y de los costes de la cooperación social implica, pues, un punto de equilibrio definitivo para la estabilidad definitiva del orden constitucional.

B. Barry, La justicia como imparcialidad. Barcelona, Paidós, 1997, p. 71.

39 D. Gauthier, Egoísmo, moralidad y sociedad liberal. Barcelona, Paidós, 1998, p. 37. 
Höffe ilustra esta idea retomando la tesis de Kant, formulada en el "Suplemento primero" de su Escrito sobre la paz de que incluso un pueblo de demonios (dotados de entendimiento) está en condiciones de establecer un Estado republicano.

Höffe recurre a este famoso pasaje del "pueblo de demonios" para poner de relieve que el ordenamiento político exigido por el principio de la ventaja distributiva puede también justificarse a través del cálculo ponderado de los individuos que han de formar parte del mismo. Con ello Höffe también quiere mostrar que el "principio de la ventaja distributiva", a diferencia del "principio del beneficio mutuo", contiene una pauta normativa para enjuiciar las instituciones políticas y el orden constitucional. La relevancia de este pasaje reside para Höffe, en que en él Kant pone de relieve que los propios demonios están en condiciones de aprender a través de una ponderación inteligente de sus intereses que sólo un ordenamiento constitucional republicano puede garantizar a cada uno de ellos el máximo espacio de libertad posible para perseguir y realizar sus propios fines. En este sentido, el principio de la ventaja distributiva coincide con el interés bien entendido de todos los participantes en la cooperación social. De hecho, el principio de la ventaja distributiva tiene el mismo contenido normativo que la "ley universal del derecho" que presenta Kant en la "Doctrina del derecho" de la Metafísica de las Costumbres, con la única salvedad de que él formula este principio desde la óptica de los intereses racionales de sus destinatarios. Tanto en un caso, como en otro, una dominación política "justa" es aquella que garantiza el mismo espacio de libertad para cada uno de sus miembros, limitando simetría, recíproca y universalmente el uso externo de la libertad de cada uno de ellos.

Al igual que la ley universal del derecho, el principio de la ventaja distributiva exige una repartición geométrica de los derechos y deberes a través de sus instituciones. En el caso de la filosofía jurídica de Kant, una constitución republicana es aquella que mejor se acomoda a la "ley universal del derecho" y, por tanto, a la forma de Estado que se sigue de los dictámenes de la razón pura práctico-jurídica. Pero también desde un punto de vista puramente instrumental, como el que manejan los demonios, la constitución republicana es la mejor constitución posible porque garantiza a todos ellos y en la misma medida el uso de su libertad externa. El "test de los demonios (Teufel-Test)" ${ }^{\prime 40}$ hace patente que el principio de la ventaja distributiva, esto es, el punto de vista de la justicia política, coincide con el propio autointerés de los que tienen que someterse a un ordenamiento jurídico.

La "ley universal del derecho", y el "principio de la ventaja distributiva" expresan que sólo una constitución republicana o un "Estado democrático de derecho" están en condiciones de poder ser asentidos por todos sus miembros. Ni el utilitarismo político, ni tampoco las teorías económicas de la justicia pueden llegar a este resultado normativo. Frente a la desconsideración utilitarista de las cargas individuales que acarrea la cooperación social cuando ésta no está repartida de una manera distributiva entre todos sus miembros y frente al formalismo normativo de las justicias económicas de la justicia, para las cuales todo ordenamiento jurídico es legítimo mientras que suponga un beneficio recíproco entre sus miembros, el principio de la justicia política de Höffe exige un reparto igualitario de las cargas y beneficios de la cooperación social, es decir, "que los beneficios colectivos de las instituciones sociales no lo sean solamente a favor de unos y, en cambio para el

40 O. Höffe, Demokratie im Zeitalter der Globalisierung, op. cit., p. 431. 
resto supongan únicamente o mayoritariamente perjuicios"41. Con ello obtiene la justicia política un principio normativo "fuerte" para enjuiciar cualquier ordenamiento jurídico dado. Gracias al principio de la ventaja distributiva, la teoría de la justicia política de Höffe puede escapar a la antinomia de lo político, ir más allá del positivismo jurídico y sustituir la utopía anarquista de una sociedad ausente de toda dominación política por la utopía realizable y más deseable de un ordenamiento jurídico-estatal "justo". 